\title{
Identification of Pueraria spp. through DNA barcoding and comparative transcriptomics
}

\author{
Laci M. Adolfo ${ }^{1 \dagger}$, Xiaolan Rao ${ }^{2 \dagger}$ and Richard A. Dixon ${ }^{1 *}$ (D)
}

\begin{abstract}
Background: Kudzu is a term used generically to describe members of the genus Pueraria. Kudzu roots have been used for centuries in traditional Chinese medicine in view of their high levels of beneficial isoflavones including the unique 8-C-glycoside of daidzein, puerarin. In the US, kudzu is seen as a noxious weed causing ecological and economic damage. However, not all kudzu species make puerarin or are equally invasive. Kudzu remains difficult to identify due to its diverse morphology and inconsistent nomenclature.

Results: We have generated sequences for the internal transcribed spacer 2 (ITS2) and maturase K (matK) regions of Pueraria montana lobata, P. montana montana, and P. phaseoloides, and identified two accessions previously used for differential analysis of puerarin biosynthesis as P. lobata and P. phaseoloides. Additionally, we have generated root transcriptomes for the puerarin-producing P. m. lobata and the non-puerarin producing P. phaseoloides. Within the transcriptomes, microsatellites were identified to aid in species identification as well as population diversity.

Conclusions: The barcode sequences generated will aid in fast and efficient identification of the three kudzu species. Additionally, the microsatellites identified from the transcriptomes will aid in genetic analysis. The root transcriptomes also provide a molecular toolkit for comparative gene expression analysis towards elucidation of the biosynthesis of kudzu phytochemicals.
\end{abstract}

Keywords: Kudzu, DNA barcoding, Microsatellites, Comparative transcriptomics

\section{Summary}

Various kudzu accessions were analyzed through barcoding and comparative transcriptomics, generating tools for identification and molecular pathway analysis.

\section{Background}

Kudzu has been used in traditional Chinese medicine with the roots being considered the most valuable part of the plant [1]. The high levels of isoflavones in the roots are believed to be important for the medicinal properties of kudzu [2]. Kudzu contains the same major isoflavones

*Correspondence: Richard.Dixon@unt.edu

${ }^{\dagger}$ Laci M. Adolfo and Xiaolan Rao contributed equally to this work.

${ }^{1}$ BioDiscovery Institute and Department of Biological Sciences, University

of North Texas, 1155 Union Circle \#305220, Denton, TX 76203-5017, USA

Full list of author information is available at the end of the article that are found in other legumes, including the aglycones daidzein, genistein, and formononetin as well as their $\mathrm{O}$-glycosides daidzin, genistin, and ononin. However, kudzu also contains puerarin, the 8-C-glycoside of daidzein [3]. Many of the health benefits of kudzu are believed to come from puerarin, because the carboncarbon glycosidic bond in puerarin makes it resistant to hydrolysis when ingested [2]. However, health benefits have also been linked to daidzin and genistin, as well as the methylated isoflavone formononetin and its glycoside, ononin. A Chinese pharmacopeia dating back to 200 B.C. mentions the roots of kudzu and their use in various treatments. Kudzu was administered to help with a range of ailments including inflammation, diarrhea, and even alcoholism [4]. In its native habitat, Asia, kudzu grows well with growth being controlled by pests and 
climate. In the US, kudzu is an invasive weed, especially in the southeast [5].

Mass planting of kudzu allowed it to spread rapidly throughout the Southeast US, where the climate is perfect for it, with high temperatures and plenty of rainfall, and natural predators are absent. Kudzu vines can grow up to 12 in. a day. Kudzu out-competed native flora and caused an economic burden as the vines crept up utility poles and disrupted power [5]. The removal of kudzu is a difficult process as simply removing the top foliage does not stop the spread of the plant; kudzu's extensive root system includes a large tap root from which many roots and vines sprout $[6,7])$. The US federal government declared kudzu a federal noxious weed in the mid to late 1990's. It was eventually removed from the federal noxious weed list; however, it is still on the noxious weed lists of several states, including Texas [7].

The taxonomy of kudzu is unclear, with multiple synonyms and multiple varieties within species, such as Pueraria montana, $P$. thomsonii, and $P$. lobata which can also be referred to as $P$. montana var. montana, $P$. montana var. chinensis, and $P$. montana var. lobata, respectively. The classification as different species and different variants has been confusing, especially as the morphological characteristics of these individual varieties are highly variable $[8,9]$.

The availability of established DNA barcodes that can differentiate between different species/varieties would allow for positive identification of kudzu in the wild, and could aid ecological studies; for example, fecal samples are often examined to determine the dietary behavior of animals and insects [10-12]. Furthermore, DNA barcoding could facilitate quality control and assurance for herbal supplements [13-15].

A previous study used kudzu accessions collected in the field (Ardmore, OK) and obtained commercially (Kudzu Kingdom, Kodak, TN) to interrogate puerarin biosynthesis through differential expression analysis following EST sequencing [16]. To aid the identification of these and other kudzu accessions, we have generated barcodes for the ITS2 and matK regions of three kudzu species/ varieties. We have also generated transcriptomic data of the roots of the puerarin producing $P$. m. lobata and the non-puerarin producing $P$. phaseoloides. The transcriptomic data generated allows for differential gene expression analysis and also identifies simple sequence repeat (SSRs) markers between the two kudzu species. These genomic resources will serve as references for identifying kudzu species for eradication, harvesting of phytochemicals, validation of supplements, and ecological research. Additionally, the comparative transcriptomics provides a molecular resource for exploring genes active in the synthesis of valuable phytochemicals.

\section{Results}

\section{Seed morphology}

The origins of the kudzu accessions analyzed in the present work are provided in the Methods. Wild kudzu collected from Oklahoma and Texas, and USDA PI 434246 and PI 9227 all had kidney-shaped seeds. Most of the seeds were dark brown with a few being lighter brown to reddish. The seeds also had lighter colored striations. They measured approximately $3.2 \mathrm{~mm}$ in length (Fig. 1AD). The Kudzu Kingdom, BRSEEDS, USDA PI 308576, and USDA DLEG 890244 seeds were rectangular to oblong. The seed colors ranged from maroon to orange to golden yellow and were also approximately $3.2 \mathrm{~mm}$ in length (Fig. 1F-I). The USDA PI 298615 seeds were rectangular to oblong, and dark to medium brown in color. They were smaller than the other seeds, measuring approximately $2.1 \mathrm{~mm}$ in length (Fig. 1E).

\section{Plant morphology}

All plants grew as vines with trifoliate leaves and trichomes present on the leaves and stems/vines (Supplemental Fig. 1). DLEG 890244 (P. phaseoloides) did not germinate so analysis of the whole plant, plant parts, and roots was not possible. The wild kudzu accessions as well as the $P$. m. lobata accessions all had prominent trichomes as did the commercial and $P$. phaseoloides accessions; however, the trichomes present on the $P . m$. montana accession were less pronounced. The P. m. montana plants also had smaller, almond shaped leaves and thinner vines as compared to the other plants (Fig. 2). The thinner vines on $P$. m. montana made the vines more malleable. The leaves of the commercial and the $P$. phaseoloides accessions were rounder than the $P . m$. montana accession. Interestingly, the leaves of the wild and P. $m$. lobata accessions tended to vary even among the same accession (Supplemental Fig. 2). While some of the $P$. $m$. lobata leaves were rounder, similar to that of the commercial and $P$. phaseoloides accessions, others were lobed. The lobing on the P. m. lobata leaves also varied from slight to deep lobing. However, irrespective of their overall shape, the leaves of the wild and P. m. lobata accessions tended to come to a sharp point.

\section{Isoflavone content}

An examination of the roots of all eight accessions revealed that the Oklahoma and Texas collected material and the $P$. m. lobata accessions all contained puerarin. In contrast, the commercial, $P$. phaseoloides, and $P$. m. montana accessions did not contain puerarin (Fig. 3). In addition to puerarin, roots of the wild and $P$. m. lobata accessions contained daidzin and daidzein. Other isoflavones, including genistein, genistin, and ononin were present in reduced amounts in the wild and $P . m$. lobata 


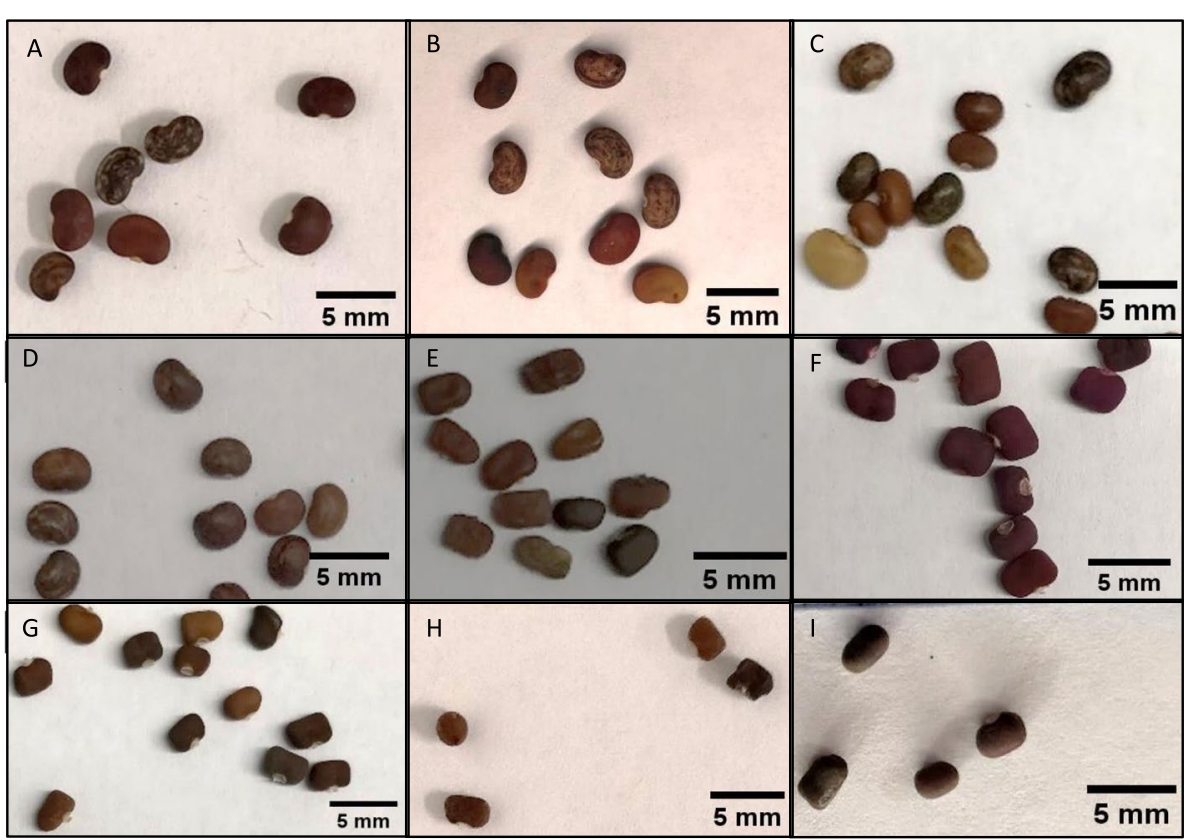

Fig. 1 Morphology of seeds from each kudzu accession. A Oklahoma (wild); B Texas (wild); C PI 9227 (P. m. lobata); D PI 434246 (P. m. lobata); E PI 298615 (P. m. montana); F Kudzu Kingdom (commercial); G BRSEEDS (commercial); H PI 308576 (P. phaseoloides); I DLEG 890244 (P. phaseoloides)

accessions. The commercial and P. phaseoloides roots contained a higher proportion of genistein, ononin, and genistin than the Oklahoma and Texas material, $P . m$. lobata, and P. m. montana roots. In fact, those three isoflavones were found in the highest proportion in roots of the commercial and P. phaseoloides accessions. The P. $m$. montana roots contained the least amount of isoflavones based on HPLC peak areas, and these were mainly daidzin and daidzein (Fig. 3C). While not containing puerarin, the commercial kudzu and $P$. phaseoloides had higher percentages of daidzein and genistein aglycones among their isoflavone complement (Supplemental Fig. 3).

\section{Internal transcribed spacer 2 sequencing}

The internal transcribed spacer 2 (ITS2) region is generally between 200 and $250 \mathrm{bp}$. Given its small size, the entire region was able to be captured using primers from the 5.8S rRNA and 26S rRNA regions that flank the ITS2, resulting in amplicons of $425-475 \mathrm{bp}$. An Illumina MiSeq with paired end reads $2 \times 300$ was used, allowing for an overlap in the middle of the sequence. Following trimming and alignment, the whole sequenced amplicon was $468 \mathrm{bp}$ for $P$. $m$. lobata, $449 \mathrm{bp}$ for $P$. phaseoloides, and $436 \mathrm{bp}$ for $P$. $m$. montana. The ITS2 region within the whole amplicon sequence was $242 \mathrm{bp}$ for $P$. m. lobata, 224 bp for $P$. phaseoloides, and 211 bp for $P$. m. montana.

There were 80 nucleotide differences observed in comparisons between the P. m. lobata and the P. phaseoloides groups in the ITS2 region (Supplemental Table 1). Additional differences in the ITS2 regions were 18 nucleotide insertions/deletions (indels) in the $P$. phaseoloides group including one stretch of eight deleted nucleotides and one stretch of ten nucleotides (Supplemental Table 2). Comparisons between the P. m. lobata and the P. m. montana groups revealed 55 nucleotide differences (Supplemental Table 3) and 31 indels including one stretch of 19 deleted nucleotides in the $P . m$. montana group (Supplemental Table 4). The comparisons between P. phaseoloides and the P. m. montana groups had 51 nucleotide differences (Supplemental Table 5) and 17 indels (Supplemental Table 6).

\section{Maturase $\mathrm{K}$ (matK) sequencing}

Of the $\sim 1500 \mathrm{bp}$ matK chloroplast gene, approximately $776 \mathrm{bp}$ were amplified from the kudzu accessions using primers suggested by Yu et al. (2011) [17] for having high fidelity with angiosperms given the low nucleotide diversity found in these regions. Given the length of the amplicon to be sequenced, Sanger sequencing was used.

Following trimming and alignment of the matK sequences there were 17 single nucleotide polymorphisms (SNPs) identified between the P. phaseoloides and P. $m$. lobata groups, 20 SNPs identified between the P. $m$. lobata and $P$. $m$. montana groups, and 26 SNPs identified between the $P$. phaseoloides and $P$. m. montana groups (Table 1). Given that matK is a coding region, the amino 


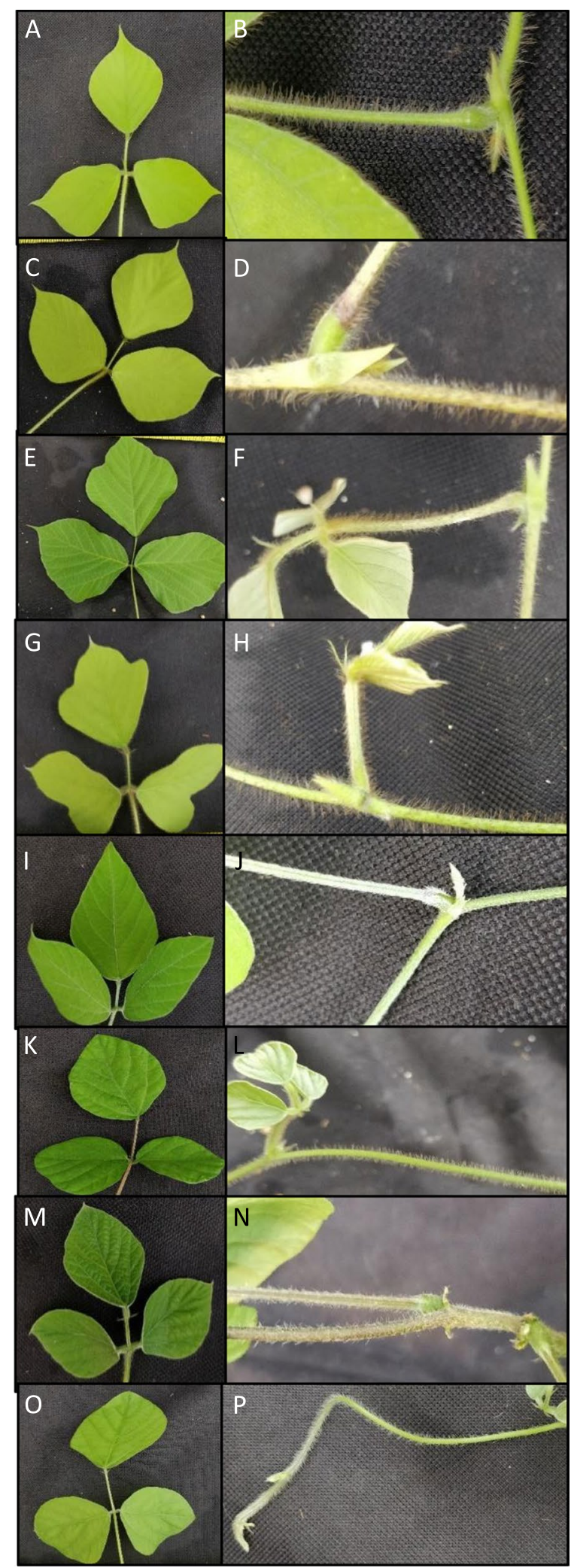

Fig. 2 Images of vines, leaves, and trichomes for each plant accession. A-B Oklahoma (wild); C-D, Texas (wild); E-F PI 9227 (P. m. lobata); G-H PI 434246 (P. m. lobata); I-J, PI 298615 (P. m. montana); K-L Kudzu Kingdom (commercial); M-N BRSEEDS (commercial); O-P PI 308576 (P. phaseoloides)

acid substitutions that resulted from the SNPs were also examined. There were eight amino acid substitutions between the $P$. phaseoloides and $P$. m. lobata groups, 12 between the $P$. $m$. lobata and $P$. $m$. montana groups, and 15 between the $P$. phaseoloides and $P$. m. montana groups (Table 2).

\section{Phylogenetic analysis}

A neighbor-joining phylogenetic tree was generated using the ITS2 and matK sequences. For the ITS2 phylogenetic tree the generated sequences were combined with sequences published in NCBI for kudzu species as well as other legumes. The results in Fig. 4 show that the $P$. phaseoloides and commercial accessions clustered together with a previously published $P$. phaseoloides ITS2 sequence from NCBI. Additionally, the P. m. lobata and Texas and Oklahoma ITS2 sequences clustered with $P$. $m$. lobata and P. montana sequences published at NCBI, along with a singular $P$. $m$. thomsonii sequence. The $P . m$. montana sequences clustered separately.

The phylogenetic tree for the matK sequences revealed similar clustering as the ITS2 phylogenetic tree. The $P$. phaseoloides and commercial kudzu matK sequences clustered with published matK sequences for $P$. phaseoloides and N. phaseoloides (formerly P. phaseoloides). The matK sequences of the $P$. m. lobata and Oklahoma and Texas accessions were clustered with a few $P . m$. lobata and $P$. montana sequences plus singular $P$. $m$. thomsonii and $P$. pseudohirsuta sequences available NCBI. However, the $P$. m. lobata, Oklahoma, and Texas kudzu matK sequences did not cluster as closely with many of the $P$. $m$. lobata and $P$. montana matK sequences analyzed from NCBI as they did in the ITS2 neighbor-joining tree. The P. m. montana matK sequences also clustered separately again, but this time they were grouped closer to other species showing more similarity to the matK sequences of Glycine spp (Fig. 5).

\section{Transcriptome sequencing and assembly}

To obtain Pueraria root transcriptomes, RNA was extracted and cDNA prepared from roots of Kudzu Kingdom (P. phaseoloides) and Oklahoma (P. m. lobata) accessions, and sequenced by the Illumina Hiseq2000 platform. The $100 \mathrm{bp}$ paired-end Illumina reads were trimmed with quality scores. Clean sequence reads from $P$. phaseoloides and $P$. m. lobata were assembled 


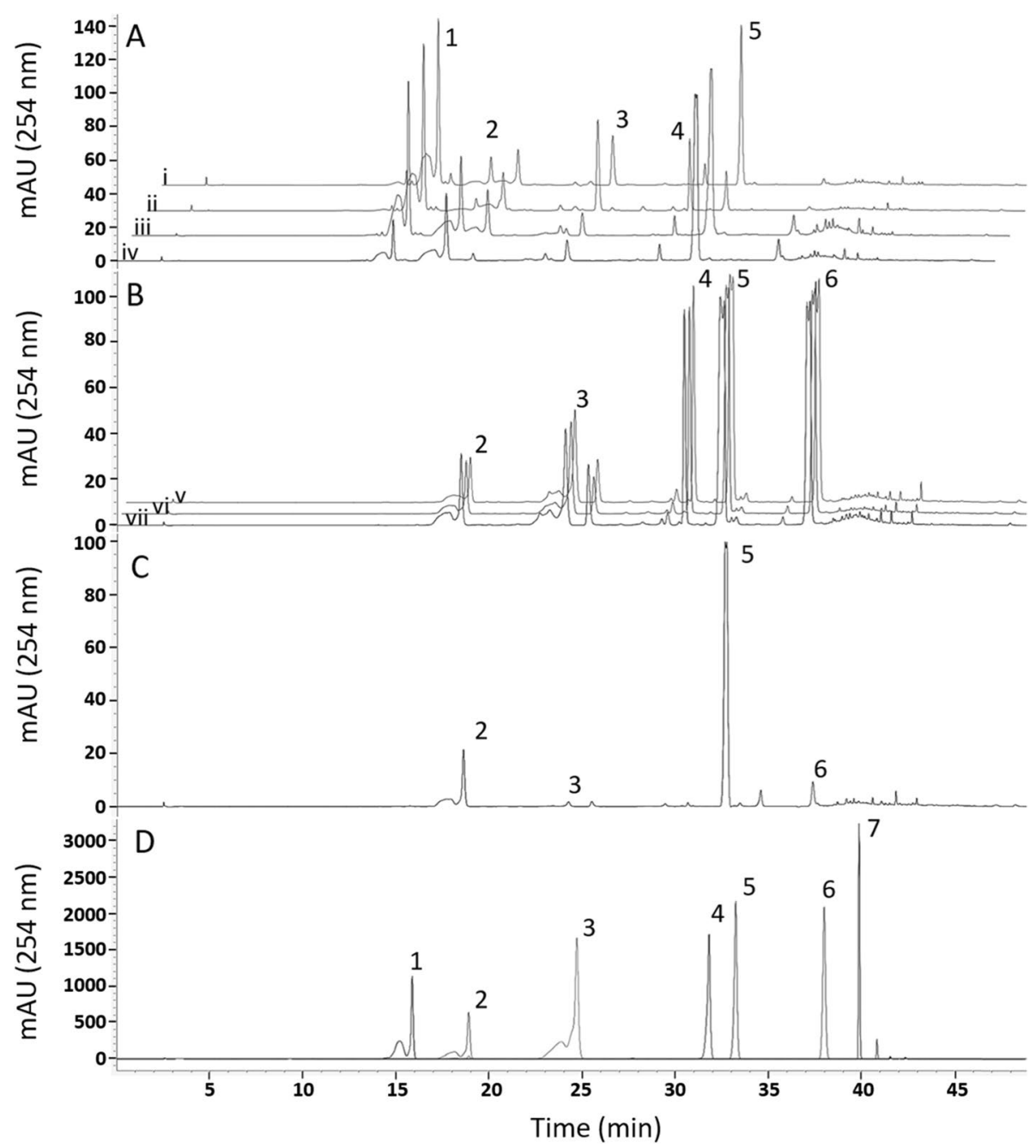

Fig. 3 Isoflavone profiles of the roots of the eight accessions examined. A HPLC chromatogram showing the isoflavone profiles of the wild and P. $m$. lobata roots (a. PI 9227, b. PI 434246, c. Oklahoma, d. Texas); B The isoflavone profiles of the commercial and P. phaseoloides roots (a. Kudzu Kingdom, b. BRSEEDS, c. PI 308576); C The isoflavone profile of the P. m. montana roots (PI 298615); D Isoflavone standards. mAU is milli-absorbance units. 1.

Puerarin, 2. Daidzin, 3. Genistin, 4. Ononin, 5. Daidzein, 6. Genistein, 7. Formononetin

separately using a combination of the programs Velvet [18] and Oases [19]. To optimize the assembly, Velvet/ Oases were run with different k-mer sizes $(31,43,55,67$, 79 and $91 \mathrm{nt})$.

Several assembly-quality parameters were assessed, including the ratio of using reads, median coverage depth, the number of contigs, the number of transcripts, the number of loci, average transcript length, and the N50 values of contigs and transcripts (Supplemental Table 7, Supplemental Fig. 4). N50 represents the sequence length $\mathrm{L}$ for which half of the bases in the assembly are in sequences of length $\mathrm{N}>=\mathrm{L}$. [20-22] Of the six k-mer tests in Velvet/Oases, a good balance for the above parameters was found at k-mer 55 assembly, resulting in 47,011 and 49,277 transcripts for $P$. phaseoloides and P. m. lobata, respectively. The full comparison of the transcriptome data for P. phaseoloides and P. $\mathrm{m}$. lobata is given in Table 3.

To further demonstrate the quality of the assembled transcripts, the length distribution of the contigs in the two transcriptomes is shown in Supplemental Fig. 5. The N50 values of transcriptomes in P. phaseoloides and P. $m$. lobata were 1988 and $1881 \mathrm{bp}$, respectively. For further quality control, we mapped the assembled transcriptomes to kudzu ESTs available from GenBank (6365 ESTs) and observed that 81\% (5183 ESTs) and 96\% (6110 ESTs) of known EST sequences were represented in our transcriptome sets for $P$. phaseoloides and $P$. m. lobata, 
Table 1 Maturase K (matK) SNP analysis

\begin{tabular}{|c|c|c|c|c|}
\hline \multirow[t]{2}{*}{ Position } & \multicolumn{3}{|l|}{ SNP } & \multirow[t]{2}{*}{ Type } \\
\hline & P. phaseoloides & P. m. lobata & P. m. montana & \\
\hline 562 & C & $C$ & A & Transversion \\
\hline 569 & C & C & G & Transversion \\
\hline 581 & G & $\mathrm{T}$ & $C$ & Variable \\
\hline 606 & G & $\mathrm{T}$ & $\mathrm{T}$ & Transversion \\
\hline 706 & T & $\mathrm{T}$ & G & Transversion \\
\hline $713-714$ & $\mathrm{TT}$ & GC & GC & Transversion/Transition \\
\hline 780 & $\mathrm{~T}$ & $\mathrm{~T}$ & C & Transition \\
\hline 807 & $\mathrm{~T}$ & $\mathrm{~T}$ & G & Transversion \\
\hline 810 & G & $\mathrm{T}$ & $\mathrm{T}$ & Transversion \\
\hline 828 & $\mathrm{~T}$ & $\mathrm{~T}$ & C & Transition \\
\hline 846 & A & A & C & Transversion \\
\hline 891 & G & A & $A$ & Transition \\
\hline 894 & $\mathrm{~T}$ & $C$ & C & Transition \\
\hline 905 & C & A & A & Transversion \\
\hline 917 & A & A & G & Transition \\
\hline 942 & $\mathrm{~T}$ & A & A & Transversion \\
\hline 948 & A & G & G & Transition \\
\hline 954 & T & G & $\mathrm{T}$ & Transversion \\
\hline 966 & A & C & A & Transversion \\
\hline 990 & G & A & G & Transition \\
\hline 1012 & C & C & $\mathrm{T}$ & Transition \\
\hline 1014 & A & C & A & Transversion \\
\hline 1022 & C & C & $\mathrm{T}$ & Transition \\
\hline 1023 & C & A & A & Transversion \\
\hline 1044 & G & A & G & Transition \\
\hline 1045 & C & $C$ & A & Transversion \\
\hline 1073 & T & $\mathrm{T}$ & G & Transversion \\
\hline 1090 & A & A & C & Transversion \\
\hline 1098 & T & A & A & Transversion \\
\hline 1118 & C & C & $\mathrm{T}$ & Transition \\
\hline
\end{tabular}

respectively. Kudzu ESTs were provided from a subtractive library with the $P$. phaseoloides root cDNA as the driver and $P . m$. lobata root cDNA as the target [16]. It is therefore reasonable that more kudzu ESTs are represented in the $P . m$. lobata root transcriptome set than in the $P$. phaseoloides set.

\section{Simple sequence repeats (SSRs) in the Pueraria root transcriptomes}

Simple sequence repeats (SSRs) or microsatellites have been broadly used as molecular markers in markerassisted selection for DNA fingerprinting [23, 24]. To supply SSR markers for distinguishing between $P$. phaseoloides and P. m. lobata, we used the MISA scripts program [25] to scan the Pueraria root transcriptomes to identify gene-derived SSR markers. In total, we detected 9220 and 6665 SSRs within 6729 and 5370 different transcripts from the $P$. phaseoloides and $P$. $m$. lobata de novo assembled transcriptomes, respectively. The putative SSRs are summarized in Supplemental Dataset 1. Excluding mono-repeats (3246 and 2625), 5974 and 4040 SSRs (dinucleotide to hexanucleotide repeats) were identified within 4516 (13.6\%) and 3373 (9.7\%) transcripts of $P$. phaseoloides and $P$. $m$. lobata, respectively. The average frequency of SSRs was one per $5.93 \mathrm{~kb}$ and $8.53 \mathrm{~kb}$ of the transcriptome sequence in $P$. phaseoloides and $P$. $m$. lobata, respectively. Among dinucleotide to hexanucleotide repeats, the distribution of SSRs was as follows: di- (2143, $35.9 \%$ and $1138,28.2 \%)$; tri- $(3255,54.5 \%$ and 2606 , $64.5 \%)$; tetra- (204, $0.03 \%$ and $116,0.03 \%)$; penta- (138, $0.02 \%$ and $80,0.02 \%)$ and hexa- (234, $0.04 \%$ and 100 , $0.02 \%)$ in $P$. phaseoloides and P. m. lobata transcripts, respectively. 
Table 2 Maturase K (matK) amino acid substitutions

\begin{tabular}{llll}
\hline Position & \multicolumn{2}{l}{ Amino acid substitutions } \\
\cline { 2 - 4 } & P.phaseoloides & P. m. lobata & $\begin{array}{l}\text { P. } \text { m. } \\
\text { montana }\end{array}$ \\
\hline 188 & $\mathrm{~L}$ & $\mathrm{~L}$ & $\mathrm{I}$ \\
190 & $\mathrm{~T}$ & $\mathrm{~T}$ & $\mathrm{~S}$ \\
194 & $\mathrm{~W}$ & $\mathrm{~L}$ & $\mathrm{~S}$ \\
202 & $\mathrm{R}$ & $\mathrm{S}$ & $\mathrm{S}$ \\
236 & $\mathrm{Y}$ & $\mathrm{Y}$ & $\mathrm{D}$ \\
238 & $\mathrm{~L}$ & $\mathrm{R}$ & $\mathrm{R}$ \\
269 & $\mathrm{~N}$ & $\mathrm{~K}$ & $\mathrm{~K}$ \\
270 & $\mathrm{E}$ & $\mathrm{D}$ & $\mathrm{D}$ \\
302 & $\mathrm{~S}$ & $\mathrm{Y}$ & $\mathrm{Y}$ \\
306 & $\mathrm{Y}$ & $\mathrm{Y}$ & $\mathrm{C}$ \\
318 & $\mathrm{H}$ & $\mathrm{Q}$ & $\mathrm{H}$ \\
322 & $\mathrm{~L}$ & $\mathrm{~F}$ & $\mathrm{~L}$ \\
341 & $\mathrm{~S}$ & $\mathrm{~S}$ & $\mathrm{~L}$ \\
349 & $\mathrm{Q}$ & $\mathrm{Q}$ & $\mathrm{K}$ \\
358 & $\mathrm{M}$ & $\mathrm{M}$ & $\mathrm{R}$ \\
364 & $\mathrm{I}$ & $\mathrm{I}$ & $\mathrm{L}$ \\
373 & $\mathrm{~S}$ & $\mathrm{~S}$ & $\mathrm{~L}$ \\
\hline & & &
\end{tabular}

\section{Annotation, functional classification, mapping and quantitation of assembled transcripts}

The transcriptome assembly from roots of $P$. phaseoloides and $P$. m. lobata contains 47,011 and 49,277 transcript isoforms, which represent a total of 33,221 and 34,677 distinct assembled loci, respectively. Each locus may include several highly similar transcript isoforms, such as splice variants, homologs and paralogs, and sequencing errors $[16,22]$. To reduce the degree of gene redundancy, we chose the longest transcript to perform annotation as the representative of the locus.

A homology search against NR resulted in 24,850 and 27,244 annotated genes in P. phaseoloides and P. m. lobata, respectively. Among annotated genes, the most abundant genes are involved in metabolic processes according to their Gene Ontology (GO) categories using Plant GOslim ancestor terms [26-28] (Fig. 6A). Based on top hits in the NR database, Pueraria transcripts have strong homology to transcripts from soybean (Glycine max), followed by green bean (Phaseolus vulgaris), consistent with the close phylogenetic relationship between kudzu and soybean [29] (Fig. 6B).

To illustrate the coverage distribution of assembled transcripts on Glycine max as the reference genome, we aligned the transcripts to the 20 chromosomes in a $500 \mathrm{~kb}$ interval (Fig. 7). Both P. phaseoloides and P. m. lobata assembled transcripts covered all 20 soybean chromosomes without any large gap. The correlation between $P$. phaseoloides and P. m. lobata transcriptome density was
0.74, indicating genetic divergence between these two species. To pinpoint the location of polymorphisms, the SSR-bearing transcripts were uniquely anchored to the single best hit in the Glycine max genome. The inconsistency in the SSR locations between $P$. phaseoloides and $P$. $m$. lobata further indicates the genetic divergence of the two accessions.

Cross-species transcriptomic comparisons have been shown to be feasible $[30,31]$. Therefore, to obtain a comparative gene expression pattern between the two Pueraria accessions, we aligned the sequencing reads to Glycine max as the reference genome [32]. Overall, 65 and $66 \%$ of the cleaned reads from $P$. phaseoloides and P. $m$. lobata were mapped to the Glycine max protein database, respectively, and $84 \%$ of Glycine max proteins were covered with at least one mapped read (Supplemental Table 8). For each Gmax protein code, the number of matching reads was counted and the hit count was then transformed to RPKM (the reads per kilobase of transcript per million) to normalize for the number of reads available for each line [30]. The coverage of the functional classes between $P$. phaseoloides and P. m. lobata were similar (Supplemental Fig. 6A). The majority of gene categories were well represented by more than $70 \%$ of genes in each class for both mappings. Among them, 87 and 91\% of genes classified in secondary metabolism were detected in $P$. phaseoloides and P. $m$. lobata, respectively.

The average RPKM values for each accession were 19.9 and 20.3, respectively. To define "differentially expressed genes", we used the criterion of 2-fold difference in RPKM value with the filter of RPKM value above 20 between the two RNA samples. By these criteria, 1631 and 1675 genes were considered as differentially expressed in $P$. phaseoloides and P. m. lobata, respectively. Overall, genes classified in photosynthesis (PS), oxidative pentose phosphate pathway (OPP), major and minor carbohydrate $(\mathrm{CHO})$ metabolism, and secondary metabolism were enriched in $P . m$. lobata, whereas genes classified in C1-metabolism, S-assimilation, and DNA and RNA metabolism were more represented in $P$. phaseoloides (Supplemental Fig. 6B). A detailed comparison for genes enriched in secondary metabolism is shown in Supplemental Fig. 6C. It is clear that the transcriptome of P. m. lobata is enriched in genes encoding proteins involved in flavonoid biosynthesis.

\section{Discussion}

\section{Identification of kudzu species using barcoding}

With the verified samples provided by GRIN-Global, the wild collected and commercial kudzu accessions compared previously for puerarin production [16] were identified as P. montana lobata and P. phaseoloides, respectively. The ITS 2 and matK sequences for the $P . m$. 


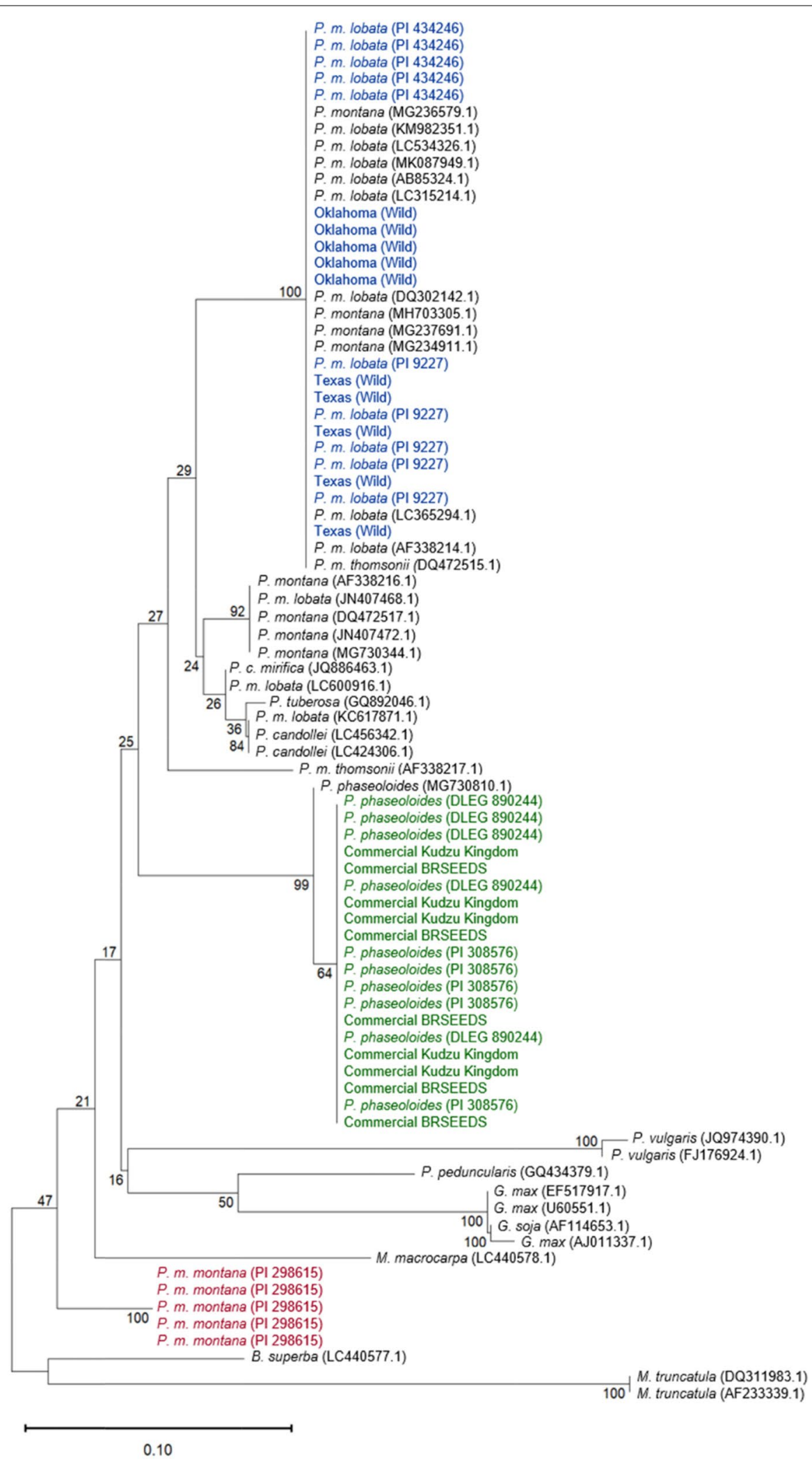

Fig. 4 Phylogenetic tree of ITS2 sequences from the Pueraria accessions in the present work (colored in blue (wild and P. m. lobata), maroon (P. m. montana), and green (commercial and P. phaseoloides)) and those published in NCBI. The scale bar indicates the length of 0.1 substitutions. The pipeline was created using phylogeny.fr and visualized in Mega 11. (Details for pipeline in Methods) 


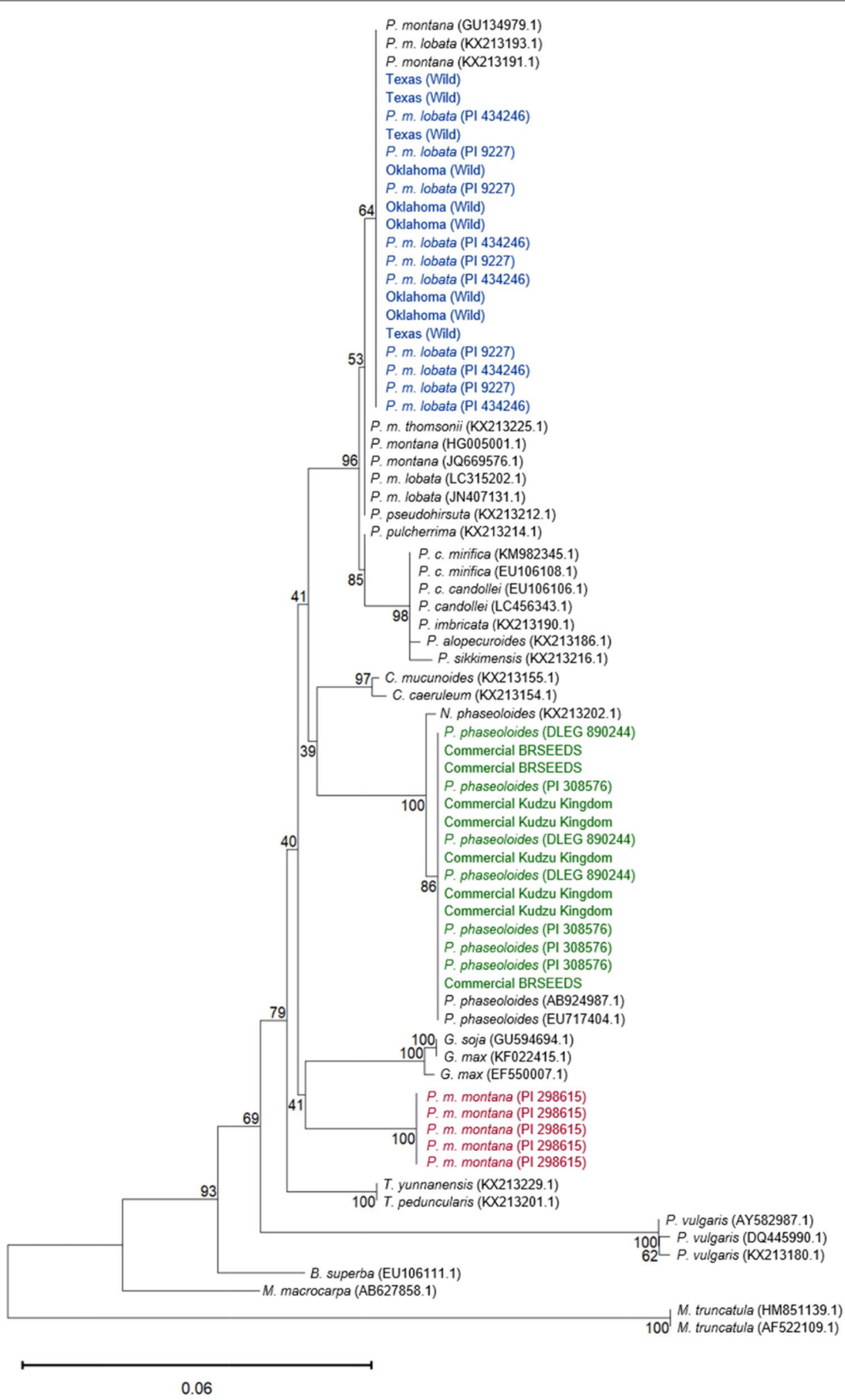

Fig. 5 Phylogenetic tree of matK sequences from the Pueraria accessions in the present work (colored in blue (wild and P. m. lobata), maroon (P. m. montana), and green (commercial and P. phaseoloides)) and those published in NCBI. The scale bar indicates the length of 0.06 substitutions. The pipeline was created using phylogeny.fr and visualized in Mega 11. (Details for pipeline in Methods) 
Table 3 Statistics of the transcriptome data

\begin{tabular}{lll}
\hline Data & P. phaseoloides & P.m. lobata \\
\hline Raw reads & $38,381,722$ & $33,214,058$ \\
Clean reads & $38,014,210$ & $32,891,280$ \\
Assembled transcripts & 47,011 & 49,277 \\
Percent assembled & 87.8 & 82.9 \\
Assembled depth & 11.9 & 10.3 \\
Mean length & 1320 & 1239 \\
\hline
\end{tabular}

lobata and Oklahoma kudzu accessions matched one another and had clear differences from the $P$. phaseoloides and commercial kudzus, which also matched one another, and had clear differences from the P. m. montana kudzu. The seed morphology of the $P$. m. montana and $P$. phaseoloides was most similar in shape while the seeds of P. $m$. lobata and P. phaseoloides were most similar in size. The plant morphology of the P. m. lobata and the P. phaseoloides was most similar with thicker vines and larger leaves. The $P . m$. lobata and wild kudzu accessions were the only plants analyzed that contained puerarin. The puerarin content for these accessions is consistent with previous reports [33].

The use of ITS2 and matK combined proved beneficial in strengthening the identification of the different
Pueraria species. Although the ITS2 region analyzed was smaller than the matK region analyzed, there were more nucleotide differences found in the ITS2 region, presumably because it is a non-coding region. The ITS 2 region varied in size for all three kudzu species analyzed, from $211 \mathrm{bp}$ to $242 \mathrm{bp}$. The primers used included a plantspecific forward primer located in the 5.8S RNA and a universal reverse primer located in the 26S RNA. The plant-specific forward primer offers benefits by reducing the unintended amplification of other organisms such as fungi. Using the primers in the $5.8 \mathrm{~S}$ and $26 \mathrm{~S}$ regions resulted in an amplicon size between 450 and $500 \mathrm{bp}$. This amplicon size was perfect for using next generation sequencing (NGS). The use of NGS helps reduce noise that can be generated from amplification and sequencing bias by allowing for greater depth of coverage. The greater coverage depth also allows for any incorrect sequences to be muffled by the true sequence. This noise was further reduced by using low cycle numbers in the amplification prior to sequencing. The difference in size can make alignment difficult; however, using primers in the relatively conserved $5.8 \mathrm{~S}$ and $26 \mathrm{~S}$ regions helps overcome alignment and amplification problems [34]. In contrast, despite the reduced number of nucleotide changes, the matK region aligned perfectly across all three species analyzed. The ease of alignment for matK is common given that it is a coding region of the chloroplast [17].
A

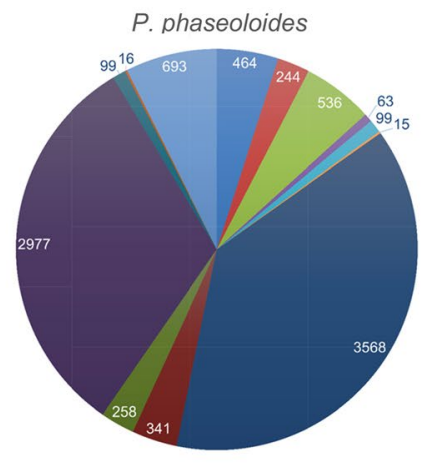

- Single-Organism Process - Meproduction - Cellular Process in Localization

B

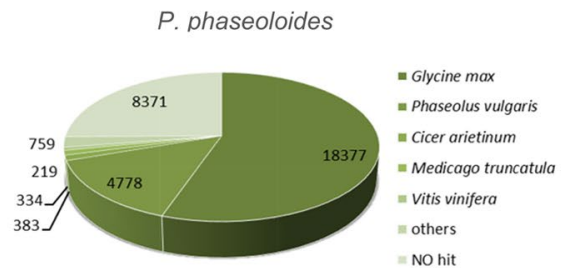

P. m. lobata

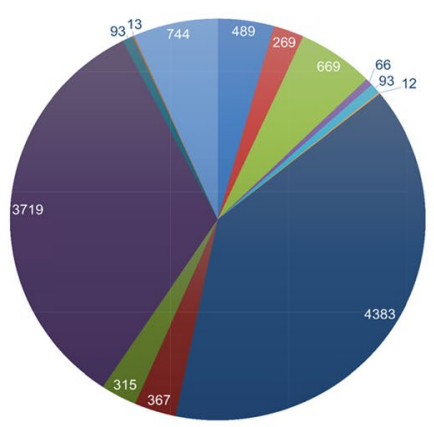

= Response to Stimulus - Cellular Component Organization or Biogenesis Growth

P. m. lobata

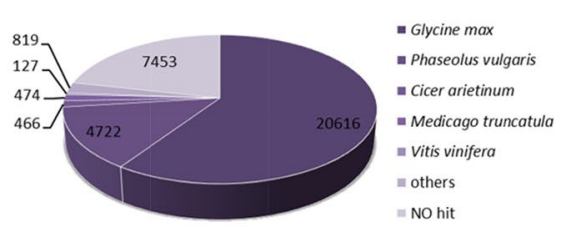

Fig. 6 Gene ontology classification and homology characteristics of Pueraria root transcript sequences. A Gene ontology analysis of the assembled transcripts. B Species distribution of homology search of Pueraria transcriptomes against the NR database 


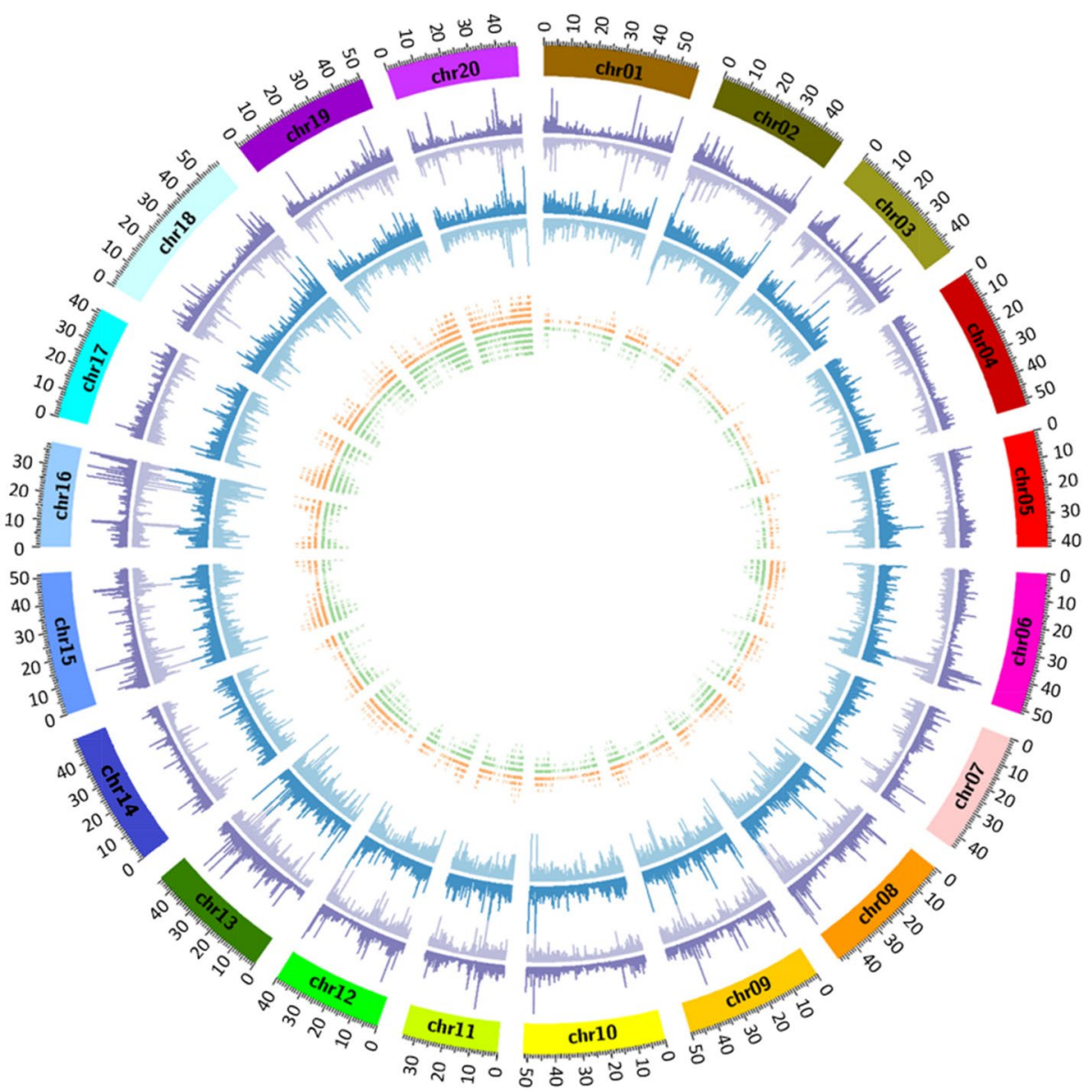

Fig. 7 Distribution of the assembled Pueraria transcripts mapped to the soybean genome. External track shows the density of P. m. lobata transcripts aligned to the Gmax genome, in both + (outside) and - (inside) strands in purple. The middle track shows the density of $P$. phaseoloides transcripts aligned to the Gmax genome, in both + (outside) and - (inside) strands in blue. Inner track show the SSR-bearing transcripts aligned to the Gmax genome sequence, with P. m. lobata strands in orange (outside) and P. phaseoloides strands in green (inside)

The use of published ITS2 and matK sequences from other plants and Pueraria species in a neighbor-joining tree with the sequences generated showed clear clustering of the $P$. phaseoloides and commercial kudzus with $P$. phaseoloides plants published in NCBI. The $P$. $m$. lobata and wild-collected Oklahoma and Texas kudzu clustered with the other P. m. lobata and P. montana sequences while the $P$. $m$. montana sequences clustered separately. The neighbor-joining trees for both genes resulted in similar clades encompassing the different accessions analyzed along with the published sequences in NCBI. Although a single concatenated tree that included both genes could have provided additional resolving power to show the relatedness of all the accessions analyzed, there was a lack of ITS2 and matK sequences in NCBI from the same samples of kudzu and other legumes, making such analysis not possible.

Unlike with animals where the cytochrome oxidase I (COI) gene of the mitochondria is considered the gold standard for species differentiation, plants do not currently have a specific region that is accepted as having good discriminatory value. However, several regions have been proposed as well as the use of two regions together $[35,36]$. The ITS2 region has been shown to have high discriminatory power in both Fabaceae genera and angiosperms [37-43]. In Vigna species, coupling matK and ITS2 increased the resolving power of the barcodes compared to using them individually [40].

The use of the ITS2 and matK regions can successfully differentiate species of the genus Pueraria as well as variants of the same species. The ITS 2 and matK for P. m. lobata and P. phaseoloides were generated from four different populations of the respective species. The sequences for the populations of each species matched one another as well as from samples within the populations. This shows that for the kudzu species analyzed, ITS2 and matK have enough nucleotide exchange to differentiate the different species but do not segregate out 
different populations of the same species. The ability of these two regions to not set apart different populations of the same species is extremely important in allowing for clear identification of kudzu species regardless of where the plant originated. The ITS2 and matK sequences generated have been uploaded to BOLD (Barcode of Life Database) [44] to be available to other researchers attempting to identify plants whether directly or through the examination of plant material present in supplements or even in the feces of organisms to understand their diet as done by Yamamoto and Uchida (2018) [12].

Interestingly, the seed and plant morphology, barcoding sequence differences, and phylogenetic separation between $P$. montana montana and P. montana lobata would suggest that these plants are more than mere varieties of the same species as suggested by van der Maesen [8]. The differences present at both a phenotypic and genotypic level for these plants align with their being separate species as previously suggested by Ohashi et al. [45]. Ohashi et al. suggest the presence of two species, $P$. montana and $P$. lobata, where P. lobata has the subspecies $P$. l. lobata and P. l. thomsonii. A comprehensive analysis of P. l. thomsonii (also known as $P$. thomsonii and P. m. chinensis) as done here for P. m. lobata, P. m. montana, and $P$. phaseoloides could discern whether $P$. $l$. thomsonii is best categorized as a subspecies of Pueraria lobata or as its own species.

\section{Summary of the transcriptome dataset}

The rapid development of next-generation sequencing (NGS) technologies has enabled discovery of novel genes by using the RNA-seq approach [46, 47]. To provide a basis for a better understanding of the bioactive natural products in kudzu, we have performed a comparative whole root transcriptome analysis. Three other reports have generated transcriptomes for different tissue types of $P$. m. lobata [48-50], and more recently, for different tissues of $P$. thomsonii and $P$. candolle $i$ var. mirifica [51, 52]. However, none of these analyses examine two different kudzu species for comparative gene expression. A previous phylogenetic study showed $80 \%$ of US kudzu analyzed had matching genotypes with one or more samples from the same population [53]. This suggest that the transcriptome generated from kudzu from Oklahoma (P. m. lobata) could be a representative genomic resource for this noxious weed that dominates throughout the Southeastern US. In Oklahoma alone a report suggests a loss of almost $\$ 168$ million in the lumber industry over 5 years [54]. Knowledge of its transcriptome can lead to development of methods of biological eradication.

It is challenging to perform de novo assembly of transcriptomes in non-model organisms lacking a reference genome. Early studies demonstrated that optimization of the transcriptome assembly using various k-mer lengths is highly desirable for de novo assemblies $[22,55,56]$. In the present study, various parameters were analyzed with a combination of Velvet and Oases. Velvet/Oases start by constructing de Bruijn graphs directly from sequencing reads, remove errors, and then resolve each de Bruijn graph to extract transcripts for each connected component (called "loci") in the graph [18, 19, 22]. Velvet/Oases allow a range of $k$-mer sizes to accommodate variation in read coverages among genes. Longer $k$-mers lead to more specificity, with lower coverage and sensitivity. Assembly quality decreases towards both lower and higher $\mathrm{k}$ values $[18,19,22]$. Assembly quality tests were performed to determine the most suitable parameter; the usage ratio of reads, depth, length, and number of assembled transcripts [22, 55, 56]. The Velvet/Oases $\mathrm{k}$-mer 55 assembly was selected as the representative for the Pueraria root transcriptomes, resulting in 47,011 and 49,277 transcripts with 33,221 and 34,677 loci, respectively. This is consistent with the gene number for the majority of sequenced plant genomes of between 20,000 and 40,000 [21].

\section{Differentiation of Pueraria species}

Simple sequence repeats (SSRs) markers have been widely used in plant genetic studies because of their tendency toward being multiallelic, expression of both parental alleles, quantity, and vast coverage in genomes [57]. Genic SSRs (derived from genes, ESTs, or cDNA clones) have some advantages over genomic SSRs including being easily generated, characterized, and possessing transferability between different species [58].

Previous markers identified to distinguish kudzus included 13 allozyme loci, 11-49 randomly amplified polymorphic DNAs (RAPDs), and 13-15 microsatellite locations [9, 53, 59-62]. Most recently, genic SSRs were identified from P. m. montana and P. phaseoloides [63]. Some of these reports used other kudzu species or varieties; however, the goal of all of them was beyond identification and focused more on population/genetic diversity and origin of kudzu's introduction. Here we identified 9220 and 6665 genic SSRs from the assembled transcripts from $P$. phaseoloides and $P$. $m$. lobata, respectively. Excluding mono-SSRs, 5974 and 4040 genic SSRs were detected in 13.6 and $9.7 \%$ of the transcripts with the frequency of one SSR per $5.93 \mathrm{~kb}$ and $8.53 \mathrm{~kb}$ in the $P$. phaseoloides and $P$. $m$. lobata transcriptomes, respectively. Frequencies of genic SSRs were reported as 1 per $3.92 \mathrm{~kb}$ or $8.63 \mathrm{~kb}$ from de novo assembled transcriptomes in the legume species lentil and chickpea, respectively [56, 64]. Additionally, the genic SSR frequency in Chinese sweetgum was 1 per $5.12 \mathrm{~kb}$ [65]. 
Factors affecting the frequency and types of SSRs include the taxon, the genomic make-up, and the SSR mining length used for analysis [66]. Here we applied the same parameters for mining microsatellites in the $P$. phaseoloides and P. m. lobata transcriptomes, so the differences in SSR frequency likely indicate differences in genomic composition. Except for mono-repeats, the most abundant SSRs were tri-nucleotide repeats (54.5 and 64.5\%), then di-nucleotide repeats (35.95 and 28.2\%) in $P$. phaseoloides and $P$. $m$. lobata transcripts, respectively. This is consistent with the observation that tri-SSRs are generally the most frequently occurring SSRs found in genic SSRs, followed by di-SSRs [58, 67]; however, there are exceptions as with Camellia japonica [68]. Among all the tri-nucleotides, AAG/CTT was found to be the most frequent motif, consistent with recent studies [69-71]. Our results suggest that the SSRs identified here are reliable and can be useful tools for assaying genetic variation in Pueraria populations.

Cross-species mapping in protein space is a viable strategy to compare different species when an equidistant reference is available [30]. Through mapping reads by alignment on the soybean protein sequence, we quantified transcript abundance in $P$. phaseoloides and $P . \mathrm{m}$. lobata. Transcripts catalogued in photosynthesis, major $\mathrm{CHO}$ metabolism and minor $\mathrm{CHO}$ metabolism were enriched in the wild-collected, invasive $P$. $m$. lobata compared with the commercial species $P$. phaseoloides. This is consistent with the competitive ability of P.m. lobata for fixing carbon [72]. Transcripts classified in secondary metabolism were also enriched in $P . m$. lobata, particularly genes involved in flavonoid biosynthesis.

\section{Conclusions}

Puerarin is found in some but not all species of Pueraria. Here we have identified the ITS 2 and matK barcodes as sufficient to differentiate between three kudzu species (P. montana, P. lobata, and P. phaseoloides), and in so doing identified the wild and commercial kudzu species used previously for preliminary gene identification in the puerarin pathway [16]. We have also provided molecular tools for more in-depth differential expression analysis of natural product pathways between transcriptomes of $P$. $m$. lobata and $P$. phaseoloides, as well as the identification of microsatellites for further use to aid in identification of the two species.

\section{Methods}

\section{Chemicals}

Daidzin, genistein, and genistin were purchased from Cayman Chemical Company (Ann Arbor, MI). All other standards were purchased from Indofine Chemical Company (Hillsborough, NJ). HPLC solvents were from
FisherSci (Walthanm, MA). Other chemicals were purchased from Sigma-Aldrich (St. Louis, MO) unless otherwise indicated.

\section{Seeds}

Oklahoma wild kudzu seeds were collected (under Texas Department of Agriculture permit no 14-NIPP-01) from $P$ street SE, near the junction with Springdale Road, in Ardmore, OK (34.159, - 97.108). The kudzu from Oklahoma had previously been identified as P. montana [73]. Kudzu Kingdom seeds were ordered from Kudzu Kingdom, a division of SunTop Inc., in Kodak, TN. Texas wild kudzu seeds were collected (under Texas Department of Agriculture permit no 19-NIPP-01) off Copeland road under Batman the ride at Six Flags Over Texas in Arlington, TX (32.759, - 97.067). The kudzu from Texas had previously been identified as $P$. $m$. lobata and validated by Texas Invaders (Site Record 19,737). BR seeds were ordered from the company BRSeeds in Araçatuba, São Paulo, Brazil as P. phaseoloides. P. montana (Lour.) Merr. var. lobata (Willd.) collected in the United States (PI 434246); P. montana (Lour.) Merr. var. lobata (Willd.) collected in Kanagawa, Japan (PI 9227); P. montana (Lour.) Merr. var. montana donated from Taiwan (PI 298615); Neustanthus phaseoloides (Roxb.) Benth. (formerly $P$. phaseoloides (Roxb.) Benth.) collected in Venezuela (PI 308576) were ordered through USDA Grin Global from the Plant Genetic Resources Conservation Unit in Griffin, GA (under Texas Department of Agriculture permit no 19-NIPP-01 where applicable). $N$. phaseoloides (DLEG 890244) seeds collected from an unknown location were ordered through USDA Grin Global from the Desert Legume Program in Tucson, AZ. Seeds ordered through USDA Grin Global were verified by an ARS Systematic Botanist and are publicly available.

\section{Seed sterilization, germination, and plant growth conditions}

Seeds were scarified in sulfuric acid for 20 min (BR seeds, Kudzu Kingdom seeds, USDA P. phaseoloides, and USDA P. montana var. montana seeds), or $45 \mathrm{~min}$ (Texas, Oklahoma, and USDA P. montana lobata (Origins Japan and US). They were then rinsed with copious amounts of water three times, dried and sterilized in $20 \%(\mathrm{v} / \mathrm{v})$ bleach for $5 \mathrm{~min}$. The seeds were allowed to dry before being plated on water agar. The plates were placed in the dark at $4{ }^{\circ} \mathrm{C}$ for 5 days, then moved to a $24^{\circ} \mathrm{C}$ light chamber and monitored for germination. Once germinated the seeds were placed in a greenhouse with temperature settings from $20^{\circ} \mathrm{C}-28^{\circ} \mathrm{C}$ and at least $14 \mathrm{~h}$ of light.

For root isoflavone analysis a young vine was cut from the main plant and the cut tip dipped in IBA (indole 3-butyric acid) before being placed in damp soil. The 
cuttings were monitored and after 4 weeks were repotted. After 8 weeks the roots were washed of excess soil and harvested for isoflavone analysis.

\section{DNA isolation}

Tissues, including leaves and seeds, were collected and placed in $2 \mathrm{~mL}$ Eppendorf tubes with a single ball bearing. The tubes were placed in liquid nitrogen and the tissue was ground using a Retsch Mixer Mill 400 at $30 \mathrm{~Hz}$ for $15 \mathrm{~s}$. The samples were then checked for degree of grinding and placed in liquid nitrogen. If the tissue was not thoroughly ground, it was run on the Retsch Mill again until efficient tissue grinding was achieved.

Tissue was suspended in $500 \mu \mathrm{L}$ of $2 \mathrm{X} \mathrm{CTAB}$ extraction buffer, vortexed for $5 \mathrm{~s}$ to mix and placed in a $60^{\circ} \mathrm{C}$ oven for $30 \mathrm{~min}$ with occasional mixing. Tissue was centrifuged at room temperature at $16,000 \mathrm{xg}$ for $5 \mathrm{~min}$. The upper liquid was transferred to a new tube being careful to avoid the tissue debris. An equal volume of cold chloroform was added to the tubes, which were then vortexed for $5 \mathrm{~s}$ and centrifuged at $4{ }^{\circ} \mathrm{C}$ for $10 \mathrm{~min}$ at 12,000 $\mathrm{x} g$. The upper aqueous phase was carefully transferred to a new tube, an equal volume of cold chloroform was added, the mixture vortexed for $5 \mathrm{~s}$ and then centrifuged at $4{ }^{\circ} \mathrm{C}$ for $10 \mathrm{~min}$ at $12,000 \mathrm{x}$. The upper aqueous phase was collected, an equal volume of cold isopropanol was added, the tube incubated at room temperature for $10 \mathrm{~min}$, and then centrifuged at $4^{\circ} \mathrm{C}$ for $10 \mathrm{~min}$ at 12,000 $\mathrm{x} g$. The liquid was carefully poured off and $1 \mathrm{~mL}$ of $70 \%$ $(\mathrm{v} / \mathrm{v})$ ethanol was added to the tube, which was centrifuged for $1 \mathrm{~min}$ at room temperature at $12,000 \mathrm{x}$ g. The liquid was again poured off, the tube re-centrifuged for $10 \mathrm{~s}$ and the remaining liquid carefully removed avoiding the pellet. The tube was briefly placed in a centrifuge with a cold trap (SpeedVac) to remove any residual ethanol. The pellet was resuspended in $50 \mu \mathrm{L}$ ddH2O. The DNA concentration was calculated on a NanoDrop ${ }^{\mathrm{TM}} 2000$.

\section{Flavonoid extraction}

Root tissue was collected from plants and placed in a $2 \mathrm{~mL}$ Eppendorf tube with a single ball bearing. The tissue was placed in liquid nitrogen before being lyophilized on a Labconco freeze dryer for 3 days. The tube was then placed in liquid nitrogen and ground on a Retsch Mixer Mill 400 at $30 \mathrm{~Hz}$ for $15 \mathrm{~s}$. Twenty mg of tissue was transferred to a new tube and remaining tissue stored at $-80^{\circ} \mathrm{C}$. The $20 \mathrm{mg}$ of tissue was resuspended in $1.5 \mathrm{~mL}$ of $80 \%(\mathrm{v} / \mathrm{v})$ methanol and sonicated for $1 \mathrm{~h}$ in an ice water ultrasonic bath (Branson, Danbury, CT). Following sonication, the tubes were placed on an end-over-end rotator at $4{ }^{\circ} \mathrm{C}$ overnight, then centrifuged for $20 \mathrm{~min}$ at $12,000 \mathrm{x}$ g. The supernatant was transferred to a new tube being careful to avoid the tissue debris pelleted at the bottom of the tube. The tubes were placed on a nitrogen evaporator (Organomation Associates Inc., Berlin, MA) to dry under a stream of air/nitrogen. After the contents of the tubes had dried, $250 \mu \mathrm{L}$ of ddH2O was added and the tubes placed on an end-over-end rotor at $4{ }^{\circ} \mathrm{C}$ for $1 \mathrm{~h}$.

Ethyl acetate extraction of flavonoids was performed twice by adding 2 times the volume of ethyl acetate to the tube, inverting to mix, and centrifuging at $12,000 \mathrm{x}$ $\mathrm{g}$ for $10 \mathrm{~min}$ at $4{ }^{\circ} \mathrm{C}$. The top layer was transferred to a new tube and dried under a stream of air/nitrogen on an Organomation nitrogen evaporator. The contents of the tubes were resuspended in $150 \mu \mathrm{L}$ of $100 \%$ methanol. The samples were then analyzed by HPLC.

\section{ITS2 metagenomic sequencing}

The ITS2 region was sequenced in collaboration with the BioDiscovery Institute (BDI) Genomics Center (Denton, TX) and Salient Genomics LLC (Krum, TX). Total DNA was used to amplify the ITS2 regions with barcode and index adapters attached to ITS2 primer sequences ITSp3/ITS-u4 [34]. The samples were prepped and run on an Illumina MiSeq (Illumina, Inc., San Diego, CA). Prior to sequencing, DNA from every accession was amplified with the ITS-p3/ITS-u4 primers to check amplicon size [34]. When run on a $1 \%$ agarose gel, all of the amplicons ran just under the $500 \mathrm{bp}$ band of the ladder, consistent with the expected amplicon size of around $450 \mathrm{bp}$. However, the size of the $P$. m. montana amplicon was slightly lower than that of the other accessions consistent with the sequencing results.

\section{matK Sanger sequencing}

DNA samples were amplified with matK primers [17] using NEB's Q5 Hot-start polymerase following the manufacturer's instructions including extension time. The annealing temperature was calculated using NEB's Tm calculator. Following amplification, the samples were sent to Eurofins Genomics (Louisville, KY) for PCR clean-up and one-pass Sanger method sequencing. To confirm the amplicons prior to sequencing, they were run on a $1 \%$ agarose gel. All the amplicons ran between the $500 \mathrm{bp}$ and $1000 \mathrm{bp}$ band of the ladder, consistent with the expected amplicon length of around $775 \mathrm{bp}$.

\section{Barcode sequence analysis}

Barcoding sequences were analyzed using Geneious Prime (San Diego, CA). Once the sequences were imported in Geneious Prime they were paired and trimmed using the BBDuk plugin to remove Illumina adapters as well as low quality (below 30 ) and short (less than $100 \mathrm{bp}$ ) reads (for ITS2 sequences). The forward and 
reversed reads were merged together using BBMerge. Merged sequences with a length between 430 and $480 \mathrm{bp}$ were extracted (for ITS2 sequences). The reads were assembled de novo using the Geneious assembler and a consensus sequence was generated for each sample. The samples were aligned for each amplicon group to identify SNPs and Indels between the three accessions.

\section{Barcoding phylogenetic trees}

The phylogenetic trees were made using a pipeline built with phylogeny.fr. The pipeline settings used MUSCLE for the sequence alignment, Gblocks for the alignment curation, and ProtDist/FastDist + BioNJ for building the phylogenetic tree with a bootstrap value of 1000 . The phylogenetic tree was viewed and edited with Mega 11 [74-81].

\section{HPLC analysis}

Twenty $\mu \mathrm{L}$ samples were injected on an Agilent 1220 Infinity II with a C18 reverse phase column. The $50 \mathrm{~min}$ run used the solvents $0.1 \%(\mathrm{v} / \mathrm{v})$ formic acid $(\mathrm{A})$ and acetonitrile (B) with a gradient as follows: $0-5 \mathrm{~min}, 95 \% \mathrm{~A}$; 5-10 min, $85 \% \mathrm{~A} ; 10-25 \mathrm{~min}, 77 \% \mathrm{~A} ; 25-30 \mathrm{~min}, 67 \% \mathrm{~A}$; 30-35 min, 60\% A; 35-40 min, 0\% A; $40-45 \mathrm{~min}, 0 \% \mathrm{~A}$; 45-50 min, $95 \%$ A with a flow rate of $1 \mathrm{~mL} / \mathrm{min}$. Absorption was measured at $254 \mathrm{~nm}$.

\section{RNA extraction, CDNA library construction and Illumina sequencing}

As described [82], each RNA-library was prepared from $1 \mu \mathrm{g}$ of total RNA isolated from one sample each of Kudzu Kingdom (P. phaseoloides) and Oklahoma (P.m. lobata) roots using TruSeq RNA Sample Prep Kits v2 (Illumina Inc., San Diego, CA), according to the manufacturer's instructions, at the Genomics Core Facility at the Noble Foundation. The prepped samples with individual indexes were pooled together to run on one Hiseq2000 lane targeting $100 \mathrm{bp}$ paired reads. The Hiseq2000 run was conducted at the Genomics Core Facility of the Oklahoma Medical Research Foundation, Oklahoma City.

\section{Short read de novo assembly of transcriptomes}

Processing of the $100 \mathrm{bp}$ paired-end Illumina reads began by interleaving the read mates for each sample into a single file and trimming bases with quality scores of 20 or less from the end of each read. Reads less than $40 \mathrm{bp}$ long after trimming were discarded along with their mates [82]. Each of the Pueraria root Illumina libraries was assembled separately using a combination of Velvet 1.2.10 [18] and Oases 0.2.08 [19]. To optimize the assembly towards higher contiguity and specificity, Velvet was run using different hash lengths ( $k$-mers 31,43 , $55,67,79$ and 91) with an average insert length of $300 \mathrm{bp}$. The results of the Velvet assemblies were then run through Oases using an insert length of $300 \mathrm{bp}$. Other parameters of Velvet and Oases were set as default.

\section{Annotation}

The assembled transcript isoforms were searched against the NCBI NR database using blastx alignment (1e-6) [83], and further annotated with default parameter values using Blast2Go [84]. After the Blast2Go mapping process, EC numbers from the KEGG pathway [85] and GO terms were generated.

\section{SSR detection}

In a pre-process step, poly- $\mathrm{T}$ (poly-A) stretches from the $5^{\prime}\left(3^{\prime}\right)$ were removed by EST-trimmer scripts [86]. Parameters were set as removing (T) 5 or (A) 5 in a range of $50 \mathrm{bp}$ on the $5^{\prime}$ - or $3^{\prime}$-end, respectively. Sequences of less than $100 \mathrm{bp}$ were discarded and sequences larger than $3000 \mathrm{bp}$ were clipped at their $3^{\prime}$ side [30]. Then trimmed sequences were analyzed using MISA scripts [30] to identify Simple Sequence Repeats (SSRs). Mono-, di, tri-, tetra-, penta- and hexanucleotide repeats with a minimum of $10,7,5,5$, 5 , and 5 subunits were regarded as SSRs, respectively.

\section{Mapping and quantification of sequence reads}

As described [30], the Illumina sequence reads were mapped onto coding sequences of the Glycine max genome (version Gmax_275_Wm82.a2.v1 download from Phytozome website) by blastx [83] with threshold as $1 \mathrm{e}-6$. To reduce multiple-mapping problems, coding sequences from primary transcripts without alternative splice sites in the Glycine max genome were used [32]. The blastx output was parsed with in-house PERL scripts to count the number of reads mapped to each Glymax protein and then to calculate the RPKM value for every Glymax protein in each library.

\footnotetext{
Abbreviations

BLAST: Basic local alignment search tool; BOLD: Barcode of life database; CHO: Carbohydrate; COI: Cytochrome oxidase I; CTAB: Cetyltrimethylammonium bromide; DNA: Deoxyribonucleic acid; EC: Enzyme nomenclature; EST: Expressed sequence tag; GO: Gene ontology; GPS: Global positioning system; GRIN: Germplasm resource information network; HPLC: High performance liquid chromatography; IBA: Indole 3-butyric acid; ITS: Internal transcribed spacer; ITS2: Internal transcribed spacer 2; KEGG: Kyoto encyclopedia of genes and genomes; matK: Maturase K; mAU: Milli-absorbance units; MISA: Microsatellite identification tool; NCBI: National center for biotechnology information; NGS: Next generation sequencing; NR: Non-redundant protein; OPP: Oxidative pentose phosphate; PCR: Polymerase chain reaction; PERL: Practical extraction and reporting language; PS: Photosynthesis; RNA: Ribonucleic acid;
} 
RPKM: Reads per kilobase of transcript per million; SNP: Single nucleotide polymorphism; SRA: Sequence read archive; SSR: Simple sequence repeat; USDA: United States Department of Agriculture.

\section{Supplementary Information}

The online version contains supplementary material available at https://doi. org/10.1186/s12870-021-03383-x.

Additional file 1: Supplemental Figure 1. Images of vines and whole plant morphology. Supplemental Figure 2. Leaves from USDA PI 9227 P. m. lobata plants. Supplemental Figure 3. Percent composition of six common isoflavones in each of the seven accessions. Supplemental Figure 4. Quality measurements for Velvet/Oases assemblies. Supplemental Figure 5. Length distribution of the assembled transcripts in $P$. phaseoloides and P. m. lobata. Supplemental Figure 6. Pathway representation analysis of the soybean transcripts mapped by Pueraria reads. Supplemental Table 1. ITS2 nucleotide changes between P. m. lobata and P. phaseoloides. Supplemental Table 2. ITS2 insertions/deletions between P. m. lobata and P. phaseoloides. Supplemental Table 3. ITS2 nucleotide changes between P. m. lobata and P. m. montana. Supplemental Table 4. ITS2 insertions/deletions between P. m. lobata and P. m. montana. Supplemental Table 5. ITS2 nucleotide changes between P. phaseoloides and P. m. montana. Supplemental Table 6. ITS2 insertions/deletions between P. phaseoloides and P. m. montana. Supplemental Table 7. Assembly statistics (Velvet/Oases) for P. phaseoloides and P. m. lobata. Supplemental Table 8. Statistics of Pueraria reads mapped to soybean by BLAST.

Additional file 2: Supplemental Dataset 1. Putative SSRs from transcripts of P. phaseoloides and P. m. lobata.

\section{Acknowledgements}

We thank the Desert Legume Program and the Plant Genetic Resources Conservation Unit, Griffin, GA in connection with GRIN-Global for supplying seeds. We thank Awinash Bhatkar of the Texas Department of Agriculture for supplying the kudzu transportation permit. We thank Sebastien Santini (CNRS/ AMU IGS UMR7256) and the PACA Bioinfo platform (supported by IBISA) for the availability and management of the phylogeny.fr website used to build neighbor-joining phylogenetic trees for barcode sequence comparison.

\section{Authors' contributions}

LMA performed DNA barcoding analysis. XR performed RNA-seq analysis. RAD conceived experiments, and funded and guided research. All authors read and approved the final manuscript.

\section{Funding}

This work was supported by the University of North Texas using start-up funds awarded to Dr. Richard Dixon. The funding body played no role in the design of the study and collection, analysis, and interpretation of data and in writing the manuscript.

\section{Availability of data and materials}

The DNA barcoding sequences are available on the BOLD system with the processIDs KUDZU002-21 to KUDZU046-21. Sequence data from this article can be found in the NCBI Sequence Read Archive (SRA) repository, NCBI SRA accession No. SRX768865. The assembled transcriptomes can be found at NCBI, accession numbers 10672212 and 10671973.

\section{Declarations}

\section{Ethics approval and consent to participate}

Not applicable.

\section{Consent for publication}

Not applicable.

\section{Competing interests}

The authors declare that they have no competing interests.

\section{Author details}

${ }^{1}$ BioDiscovery Institute and Department of Biological Sciences, University of North Texas, 1155 Union Circle \#305220, Denton, TX 76203-5017, USA. ${ }^{2}$ College of Life Sciences, Hubei University, Wuhan 430068, Hubei Province, China.

Received: 12 July 2021 Accepted: 5 December 2021

Published online: 03 January 2022

\section{References}

1. Keung WM, Vallee BL. Kudzu root: an ancient chinese source of modern antidipsotropic agents. Phytochemistry. 1998;47(4):499-506.

2. Prasain JK, Barnes S, Wyss JM. Kudzu isoflavone C-glycosides: analysis, biological activities, and metabolism. Food Front. 2021;2(3):383-9.

3. Rong H, Stevens JF, Deinzer ML, Cooman LD, Keukeleire DD. Identification of isoflavones in the roots of Pueraria lobata. Planta Med. 1998;64(7):620-7.

4. Wong KH, Li GQ, Li KM, Razmovski-Naumovski V, Chan K. Kudzu root: traditional uses and potential medicinal benefits in diabetes and cardiovascular diseases. J Ethnopharmacol. 2011;134(3):584-607.

5. Winberry JJ, Jones DM. Rise and decline of the "miracle vine": kudzu in the southern landscape. Southeast Geogr. 1973;13(2):61-70.

6. (EPPO) EaMPPO. Data sheets on quarantine pests: Pueraria lobata. 2007.

7. Loewenstein NJ, Enloe SF, Everest JW, Miller JH, Ball DM, Patterson MG. The history and use of kudzu in the southeastern United States. In: System ACE, editor; 2014

8. van der Maesen LJG. Pueraria: botanical characteristics. In: Keung WM, editor. Pueraria the genus Pueraria. London and New York: Taylor and Francis; 2002. p. 1-28.

9. Sun JH, Li ZC, Jewett DK, Britton KO, Ye WH, Ge XJ. Genetic diversity of Pueraria lobata (kudzu) and closely related taxa as revealed by intersimple sequence repeat analysis. Weed Res. 2005:45(4):255-60.

10. Hamad I, Delaporte E, Raoult D, Bittar F. Detection of termites and other insects consumed by African great apes using molecular fecal analysis. Sci Rep. 2014;4:4478.

11. Rytkonen S, Vesterinen EJ, Westerduin C, Leviakangas T, Vatka E, Mutanen $M$, et al. From feces to data: a metabarcoding method for analyzing consumed and available prey in a bird-insect food web. Ecol Evol. 2019:9(1):631-9.

12. Yamamoto $S, U$ chida K. A generalist herbivore requires a wide array of plant species to maintain its populations. Biol Conserv. 2018;228:167-74.

13. Coutinho Moraes DF, Still DW, Lum MR, Hirsch AM. DNA-based authentication of botanicals and plant-derived dietary supplements: where have we been and where are we going? Planta Med. 2015;81(9):687-95.

14. Fibigr J, Satinsky D, Solich P. Current trends in the analysis and quality control of food supplements based on plant extracts. Anal Chim Acta. 2018;1036:1-15.

15. Lopez-Gutierrez N, Romero-Gonzalez R, Vidal JLM, Frenich AG. Quality control evaluation of nutraceutical products from ginkgo biloba using liquid chromatography coupled to high resolution mass spectrometry. J Pharm Biomed Anal. 2016;121:151-60.

16. He X, Blount JW, Ge S, Tang Y, Dixon RA. A genomic approach to isoflavone biosynthesis in kudzu (Pueraria lobata). Planta. 2011;233(4):843-55.

17. Yu J, Xue J-H, Zhou S-L. New universal matK primers for DNA barcoding angiosperms. J Syst Evol. 2011:49(3):176-81.

18. Zerbino DR, Birney E. Velvet: algorithms for de novo short read assembly using de Bruijn graphs. Genome Res. 2008;18(5):821-9.

19. Schulz MH, Zerbino DR, Vingron M, Birney E. Oases: robust de novo RNAseq assembly across the dynamic range of expression levels. Bioinformatics. 2012;28(8):1086-92.

20. Rana SB, Zadlock FJ, Zhang Z, Murphy WR, Bentivegna CS. Comparison of de novo transcriptome assemblers and k-mer strategies using the killifish, Fundulus heteroclitus. PLoS One. 2016;11(4):e0153104.

21. Schliesky S, Gowik U, Weber AP, Brautigam A. RNA-seq assembly - are we there yet? Front Plant Sci. 2012;3:220.

22. Yang Y, Smith SA. Optimizing de novo assembly of short-read RNA-seq data for phylogenomics. BMC Genomics. 2013;14:328.

23. Garrido-Cardenas JA, Mesa-Valle C, Manzano-Agugliaro F. Trends in plant research using molecular markers. Planta. 2018;247(3):543-57. 
24. Taheri S, Lee Abdullah T, Yusop MR, Hanafi MM, Sahebi M, Azizi P, et al. Mining and development of novel SSR markers using next generation sequencing (NGS) data in plants. Molecules. 2018;23(2):399.

25. Thiel T, Michalek W, Varshney RK, Graner A. Exploiting EST databases for the development and characterization of gene-derived SSR-markers in barley (Hordeum vulgare L.). Theor Appl Genet. 2003;106(3):411-22.

26. Ashburner M, Ball CA, Blake JA, Botstein D, Butler H, Cherry JM, et al. Gene ontology: tool for the unification of biology. Nat Genet. 2000;25(1):25-9.

27. Consortium GO. The gene ontology resource: enriching a GOld mine. Nucleic Acids Res. 2021;49(D1):D325-D34.

28. The gene ontology resource. Available from: http://geneontology.org/. Accessed 16 Nov 2021.

29. Britton KO, Orr D, Sun J. Kudzu. Morgantown: Forest Health Technology Enterprise Team; 2002. Contract No.: FHTET-2002-04

30. Brautigam A, Kajala K, Wullenweber J, Sommer M, Gagneul D, Weber KL, et al. An mRNA blueprint for C4 photosynthesis derived from comparative transcriptomics of closely related C3 and C4 species. Plant Physiol. 2011;155(1):142-56

31. Voelckel C, Gruenheit N, Lockhart P. Evolutionary transcriptomics and proteomics: insight into plant adaptation. Trends Plant Sci. 2017;22(6):462-71.

32. Schmutz J, Cannon SB, Schlueter J, Ma J, Mitros T, Nelson W, et al. Genome sequence of the palaeopolyploid soybean. Nature. 2010:463(7278):178-83.

33. Zhu Y-P, Zhang H-M, Zeng M. Pueraria (Ge) in traditional Chinese herbal medicine. In: Keung WM, editor. Pueraria the genus Pueraria. London and New York: Taylor and Francis; 2002. p. 57-69.

34. Cheng T, Xu C, Lei L, Li C, Zhang Y, Zhou S. Barcoding the kingdom Plantae: new PCR primers for ITS regions of plants with improved universality and specificity. Mol Ecol Resour. 2016;16(1):138-49.

35. Hollingsworth PM, Graham SW, Little DP. Choosing andusing a plant DNA barcode. PLoS One. 2011;6(5):e19254.

36. Kress WJ. Plant DNA barcodes: applications today and in the future. J Syst Evol. 2017;55(4):291-307.

37. Bolson M, Smidt Ede C, Brotto ML, Silva-Pereira V. ITS and trnH-psbA as efficient DNA barcodes to identify threatened commercial woody angiosperms from southern Brazilian Atlantic rainforests. PLoS One. 2015;10(12):e0143049.

38. Kang Y, Deng Z, Zang R, Long W. DNA barcoding analysis and phylogenetic relationships of tree species in tropical cloud forests. Sci Rep. 2017;7(1):12564

39. Liu J, Shi L, Han J, Li G, Lu H, Hou J, et al. Identification of species in the angiosperm family Apiaceae using DNA barcodes. Mol Ecol Resour. 2014;14(6):1231-8.

40. Raveenadar S, Lee G-A, Lee J-R, Lee KJ, Lee S-Y, Cho G-T, et al. DNA barcodes for the assessment of phylogenetic relationships based on CpDNA and NrDNA regions in Vigna species. Plant Breed Biotechnol. 2018;6(3):285-92.

41. Tahir A, Hussain F, Ahmed N, Ghorbani A, Jamil A. Assessing universality of DNA barcoding in geographically isolated selected desert medicinal species of Fabaceae and Poaceae. PeerJ. 2018;6:e4499.

42. Wu F, Ma J, Meng Y, Zhang D, Pascal Muvunyi B, Luo K, et al. Potential DNA barcodes for Melilotus species based on five single loci and their combinations. PLoS One. 2017;12(9):e0182693.

43. Zhang D, Jiang B. Species identification in complex groups of medicinal plants based on DNA barcoding: a case study on Astragalus spp. (Fabaceae) from southwest China. Conserv Genet Resour. 2019;12(3):469-78.

44. Ratnasingham S, Hebert PD. BOLD: the barcode of life data system. Mol Ecol Notes. 2007;7(3):355-64 http://www.barcodinglife.org.

45. Ohashi H, Tateishi Y, Nemoto T, Endo Y. Taxonomic studies on the Leguminosae of Taiwan III. Sci Rep Tohoku Univ Ser 4. 1988;39:191-248.

46. Stark R, Grzelak M, Hadfield J. RNA sequencing: the teenage years. Nat Rev Genet. 2019;20(11):631-56.

47. Zhang S, Zhang L, Tai Y, Wang X, Ho CT, Wan X. Gene discovery of characteristic metabolic pathways in the tea plant (Camellia sinensis) using 'omics'-based network approaches: a future perspective. Front Plant Sci. 2018;9:480.

48. Han R, Takahashi H, Nakamura M, Yoshimoto N, Suzuki H, Shibata D, et al. Transcriptomic landscape of Pueraria lobata demonstrates potential for phytochemical study. Front Plant Sci. 2015;6:426.
49. Wang X, Li S, Li J, Li C, Zhang Y. De novo transcriptome sequencing in Pueraria lobata to identify putative genes involved in isoflavones biosynthesis. Plant Cell Rep. 2015;34(5):733-43.

50. Wang C, Xu N, Cui S. Comparative transcriptome analysis of roots, stems, and leaves of Pueraria lobata (Willd.) Ohwi: identification of genes involved in isoflavonoid biosynthesis. PeerJ. 2021;9:e10885.

51. He M, Yao Y, Li Y, Yang M, Li Y, Wu B, et al. Comprehensive transcriptome analysis reveals genes potentially involved in isoflavone biosynthesis in Pueraria thomsonii Benth. PLoS One. 2019;14(6):e0217593.

52. Suntichaikamolkul N, Tantisuwanichkul K, Prombutara P, Kobtrakul K, Zumsteg J, Wannachart S, et al. Transcriptome analysis of Pueraria candollei var. mirifica for gene discovery in the biosyntheses of isoflavones and miroestrol. BMC Plant Biol. 2019;19(1):581.

53. Bentley KE, Mauricio R. High degree of clonal reproduction and lack of large-scale geographic patterning mark the introduced range of the invasive vine, kudzu (Pueraria montana var. lobata), in North America. Am J Bot. 2016;103(8):1499-507.

54. Harron $\mathrm{P}$, Joshi $\mathrm{O}$, Edgar CB, Paudel S, Adhikari A. Predicting kudzu (Pueraria montana) spread and its economic impacts in timber industry: a case study from Oklahoma. PLoS One. 2020;15(3):e0229835.

55. Gutierrez-Gonzalez JJ, Tu ZJ, Garvin DF. Analysis and annotation of the hexaploid oat seed transcriptome. BMC Genomics. 2013;14:471

56. Verma P, Shah N, Bhatia S. Development of an expressed gene catalogue and molecular markers from the de novo assembly of short sequence reads of the lentil (Lens culinaris Medik.) transcriptome. Plant Biotechnol J. 2013;11(7):894-905

57. Powell W, Machray GC, Provan J. Polymorphism revealed by simple sequence repeats. Trends Plant Sci. 1996;1(7):215-22.

58. Varshney RK, Graner A, Sorrells ME. Genic microsatellite markers in plants: features and applications. Trends Biotechnol. 2005;23(1):48-55.

59. Heider B, Fischer E, Bernd I T, Schultze-Kraft R. Analysis of genetic variation among accessions of Pueraria montana (Lour.) Merr. var. lobata and Pueraria phaseoloides (Roxb.) Benth. based on RAPD markers. Genet Resour Crop Evol. 2006;54(3):529-42.

60. Hoffberg SL, Bentley KE, Lee JB, Myhre KE, Iwao K, Glenn TC, et al. Characterization of 15 microsatellite loci in kudzu (Pueraria montana var. lobata) from the native and introduced ranges. Conserv Genet Resour. 2014;7(2):403-5.

61. Jewett DK, Jiang CJ, Britton KO, Sun JH, Tang J. Characterizing specimens of kudzu and related taxa with RAPD's. Castanea. 2003;68(3):254-60.

62. Pappert RA, Hamrick JL, Donovan LA. Genetic variation in Pueraria lobata (Fabaceae), an introduced, clonal, invasive plant of the southeastern United States. Am J Bot. 2000;87(9):1240-5.

63. Haynsen MS, Vatanparast M, Mahadwar G, Zhu D, Moger-Reischer RZ, Doyle JJ, et al. De novo transcriptome assembly of Pueraria montana var. lobata and Neustanthus phaseoloides for the development of eSSR and SNP markers: narrowing the US origin(s) of the invasive kudzu. BMC Genomics. 2018;19(1):439.

64. Garg R, Patel RK, Jhanwar S, Priya P, Bhattacharjee A, Yadav G, et al. Gene discovery and tissue-specific transcriptome analysis in chickpea with massively parallel pyrosequencing and web resource development. Plant Physiol. 2011;156(4):1661-78.

65. Sun R, Lin F, Huang P, Zheng Y. Moderate genetic diversity and genetic differentiation in the relict tree Liquidambar formosana Hance revealed by genic simple sequence repeat markers. Front Plant Sci. 2016;7:1411.

66. Toth G, Gaspari Z, Jurka J. Microsatellites in different eukaryotic genomes: survey and analysis. Genome Res. 2000;10(7):967-81.

67. Zalapa JE, Cuevas H, Zhu H, Steffan S, Senalik D, Zeldin E, et al. Using nextgeneration sequencing approaches to isolate simple sequence repeat (SSR) loci in the plant sciences. Am J Bot. 2012;99(2):193-208.

68. Li Q, Su X, Ma H, Du K, Yang M, Chen B, et al. Development of genic SSR marker resources from RNA-seq data in Camellia japonica and their application in the genus Camellia. Sci Rep. 2021;11(1):9919.

69. Li T, Zhou H, Ma J, Dong L, Xu F, Fu X, et al. Quality assessment of licorice based on quantitative analysis of multicomponents by single marker combined with HPLC fingerprint. Evid Based Complement Alternat Med. 2021;2021:1-12.

70. Karciota H, Paizila A, Topcu H, llikcioglu E, Kafkas S. Transcriptome sequencing and development of novel genic SSR markers from Pistacia vera L. Front Genet. 2020;11:1021. 
71. Liu L, Fan X, Tan P, Wu J, Zhang H, Han C, et al. The development of SSR markers based on RNA-sequencing and its validation between and within Carex L. species. BMC Plant Biol. 2021;21(1):17.

72. SasekTW, Strain BR. Effects of carbon dioxide enrichment on the growth and morphology of kudzu (Pueraria lobata). Weed Sci. 1988;36(1):28-36.

73. Claytor M, Hickman KR. Kudzu, Pueraria montana (Lour.) Merr. abundance and distribution in Oklahoma. J Okla Native Plant Soc. 2015:15:9.

74. Castresana J. Selection of conserved blocks from multiple alignments for their use in phylogenetic analysis. Mol Biol Evol. 2000;17(4):540-52.

75. Dereeper A, Guignon V, Blanc G, Audic S, Buffet S, Chevenet F, et al. Phylogeny.fr: robust phylogenetic analysis for the non-specialist. Nucleic Acids Res. 2008;36(Web Server issue):W465-9.

76. Dereeper A, Audic S, Claverie JM, Blanc G. BLAST-EXPLORER helps you building datasets for phylogenetic analysis. BMC Evol Biol. 2010;10:8.

77. Edgar RC. MUSCLE: multiple sequence alignment with high accuracy and high throughput. Nucleic Acids Res. 2004;32(5):1792-7.

78. Elias I, Lagergren J. Fast computation of distance estimators. BMC Bioinformatics. 2007:8:89.

79. Felsenstein J. PHYLIP - phylogeny inference package (version 3.2). Cladistics. 1989;5(2):164-6.

80. Gascuel O. BIONJ: an improved version of the NJ algorithm based on a simple model of sequence data. Mol Biol Evol. 1997;14(7):685-95.

81. Tamura K, Stecher G, Kumar S. MEGA11: molecular evolutionary genetics analysis version 11. Mol Biol Evol. 2021;38(7):3022-7.

82. Rao X, Krom N, Tang Y, Widiez T, Havkin-Frenkel D, Belanger FC, et al. A deep transcriptomic analysis of pod development in the vanilla orchid (Vanilla planifolia). BMC Genomics. 2014;15:964.

83. Camacho C, Coulouris G, Avagyan V, Ma N, Papadopoulos J, Bealer K, et al. BLAST+: architecture and applications. BMC Bioinformatics. 2009;10:421.

84. Conesa A, Gotz S, Garcia-Gomez JM, Terol J, Talon M, Robles M. Blast2GO: a universal tool for annotation, visualization and analysis in functional genomics research. Bioinformatics. 2005;21(18):3674-6.

85. KEGG: Kyoto Encyclopedia of Genes and Genomes. Available from: https://www.genome.jp/kegg/. Accessed 1 Oct 2021.

86. Microsatellite Identification Tool (MISA). Available from: https://webblast. ipk-gatersleben.de/misa/.

\section{Publisher's Note}

Springer Nature remains neutral with regard to jurisdictional claims in published maps and institutional affiliations.

Ready to submit your research? Choose BMC and benefit from:

- fast, convenient online submission

- thorough peer review by experienced researchers in your field

- rapid publication on acceptance

- support for research data, including large and complex data types

- gold Open Access which fosters wider collaboration and increased citations

- maximum visibility for your research: over $100 \mathrm{M}$ website views per year

At BMC, research is always in progress.

Learn more biomedcentral.com/submissions 